\title{
Doppelnummern im April und Mai
}

Liebe Leserinnen, liebe Leser

Aufgrund der aktuellen Situation wird die Schweizerische Ärztezeitung im April und Mai nur jede zweite Woche erscheinen.

Ausgabe 15-16 erscheint am 8. April

Ausgabe 17-18 erscheint am 22. April

Ausgabe 19-20 erscheint am 6. Mai

Ausgabe 21-22 erscheint am 20. Mai

Für Fragen, Artikeleinreichungen und weitere Anliegen erreichen Sie uns am besten über: redaktion.saez@emh.ch Das SÄZ-Team dankt Ihnen für Ihr Verständnis und wünscht Ihnen speziell in diesen Tagen: «Bleiben Sie gesund!»

\section{Numéros doubles en avril et mai}

Chères lectrices, chers lecteurs,

En raison de la situation actuelle, le Bulletin des médecins suisses ne paraîtra qu'une fois toutes les deux semaines en avril et mai.

Numéro 15-16: parution le 8 avril

Numéro 17-18: parution le 22 avril

Numéro 19-20: parution le 6 mai

Numéro 21-22: parution le 20 mai

Pour toute question, envoi d'articles et autres demandes, merci de nous contacter par courriel: redaktion.saez@ emh.ch

Léquipe du BMS vous remercie de votre compréhension et vous souhaite tout particulièrement en cette période de rester en bonne santé!

\section{Numeri doppi in aprile e maggio}

Gentili lettrici, cari lettori,

a causa della situazione attuale, il Bollettino dei medici svizzeri sarà pubblicato solo ogni due settimane in aprile e maggio.

Il numero 15-16 uscirà l'8 aprile

Il numero 17-18 uscirà il 22 aprile

Il numero 19-20 uscirà il 6 maggio

Il numero 21-22 uscirà il 20 maggio

Per domande, inoltro di articoli e altre questioni, contattateci all'indirizzo: redaktion.saez@emh.ch Il team BMS vi ringrazia per la vostra comprensione e vi augura, soprattutto in questi giorni, di «restare sani»! 